\title{
Educação, política e religião na fixação do núcleo jesuíta em Itu: uma análise a partir do Colégio São Luís (1867-1918)
}

\author{
Education, Politics and Religion in the historical \\ formation of the Jesuit nucleus in Itu City: analysis \\ from St. Louis School (1867-1918)
}

\section{Ana Rosa Cloclet da Silva, Lais da Silva Lourenço*}

Pontifícia Universidade Católica de Campinas (PUC-Campinas), Campinas, SP, Brasil

\section{Resumo}

O presente artigo tem como objetivo analisar o processo de abertura e funcionamento do Colégio jesuíta São Luís de Itu, entre os anos de 1867 e 1918. Retornando ao Brasil no ano de 1856, já no contexto da denominada reforma ultramontana, a Companhia de Jesus reinicia seu projeto de evangelização, empregando a educação como uma de suas principais estratégias. Diferentemente dos séculos XVII e XVIII - quando possuíam o monopólio da educação no Brasil - tais clérigos identificaram novas demandas educacionais e pedagógicas, adaptando sua atuação e concedendo à educação um novo 
aspecto a fim de legitimá-la, alinhando-a à conjuntura do século XIX. Considerando o caráter político da educação e da religião, a partir do referencial teórico da Nova História Política, o presente artigo analisa a articulação entre os preceitos da Ordem, seu ideal de educação e os rumos da modernidade reivindicada pelas elites ituanas, tendo como foco o Colégio São Luís de Itu. Deste modo, intenciona ampliar o debate sobre o caráter político da educação, bem como sobre suas relações com o campo religioso. De forma geral, busca colaborar para o alargamento dos estudos históricos acerca da religião e dos atores e estratégias envolvidos na reforma da Igreja católica em moldes ultramontanos, no Brasil do século XIX.

Palavras-chave: Jesuítas. Educação. Religião. Política. Itu.

\section{Abstract}

This article analyzes the process of founding and functioning of the São Luís Jesuit School in Itu, between 1867 and 1918. Returning to Brazil in 1856, already in the context of the denominated "ultramontane reform", the Company of Jesus restarts its project of evangelization, employing education as one of its main strategies. Unlike the seventeenth and eighteenth centuries - when they had the monopoly of education in Brazil - these clerics identified new educational and pedagogical demands, adapting their activities and giving education a new aspect in order to legitimize it, aligned with the conjuncture of the nineteenth century. Considering the political character of education and religion, based on the theoretical reference of the New Political History, it is intended to analyze the articulation between the precepts of the Order, its ideal of education and the directions of modernity claimed by the Itu elites. Thus, it intends to broaden the debate on the political character of education, as well as on its relations with the religious field. In general, it seeks to collaborate in the extension of historical studies about religion and the actors their strategies involved in the ultramontane reform of the Catholic Church in nineteenth-century Brazil.

Keywords: Jesuits. Education. Religion. Politics. Itu. 


\section{Introdução}

No decorrer do século XIX, o processo da formação dos Estados nacionais em moldes liberais implicou a necessária adaptação e reformulação dos sistemas religiosos vigentes (HERVIEU-LÉGER, 2004, p. 37), derivando uma mescla de elementos do Antigo Regime e o racionalismo secular. Assim, não foram incomuns casos em que se buscou constituir a nação como uma comunidade de fiéis utilizando-se símbolos cristãos para "sacralizá-la", ou lançando-se mão da liturgia religiosa para comemorar a nação, processo no qual o apoio fornecido pelos religiosos à causa nacional mostrou-se fundamental (HAUPT, 2008, p. 77-94). A tal ponto que, seguindo a "antropologia do secularismo" de Tala Asad, no processo de constituição das sociedades modernas, a religião surgiu de forma paralela e em relação dialética com a formação do "secular", inviabilizando o aparecimento de Estados neutros em matéria religiosa e de "arenas públicas desnudas" (ASAD, 2003).

$\mathrm{Na}$ América Latina, algumas tendências nos modelos assumidos pela Igreja Católica foram propostas, considerando que nesses Estados os processos das independências desdobraram-se na formação de nações católicas. No caso brasileiro, dois modelos de catolicismo se alternaram no decorrer do século XIX. Até 1840, a vertente denominada "regalista" - que propunha subordinar os assuntos disciplinares da Igreja ao Estado - fora hegemônica, tendo sua origem no padroado e sendo reconfigurada durante o Império, sob influência de uma geração de clérigos influenciados pelas reformas pombalinas, sob liderança de Antônio Diogo Feijó (SILVA; LOURENÇO, 2015). Após 1840, o segundo modelo, denominado "ultramontano" - até então pouco propositivo em assuntos concernentes ao relacionamento entre Estado e Igreja no Brasil - galgara legitimidade política, implementando algumas das diretrizes do papado de Pio IX, com destaque para o dogma da infalibilidade papal e a autonomia institucional da Igreja católica.

Tal transformação fora, em grande parte, legalizada pelas reformas eleitorais de 1842 e 1846, em conjunto com a grande reforma judiciária no Império, em 1871, a partir das quais a hegemonia regalista fora alterada. Restringindo as possibilidades eletivas a militares, 
magistrados e clérigos, o Estado se esforçava para profissionalizar cargos políticos institucionais, alterando o perfil do grupo político dirigente (SANTIROCCHI, 2010, p. 110).

Ademais, a participação de clérigos de orientação regalista na Revolução Liberal eclodida nas províncias de São Paulo e Minas Gerais, no ano de 1842, também fora decisiva para a legitimidade política assumida pela tendência ultramontana, a começar pela reconfiguração do bispado nacional (SANTIROCCHI, 2010, p. 120). Intencionando solidificar a Monarquia brasileira, após 1842, D. Pedro II e seus principais conselheiros passaram a nomear bispos filiados às tendências conservadoras e monarquistas (WERNET, 1987, p. 52). O interesse do Estado em favorecer um clero apolítico (SANTIROCCHI, 2010) e, ao mesmo tempo, de secularizar a burocracia estatal, transformaram principalmente o contexto eleitoral brasileiro do período. Além disso, a partir de 1871, com o ingresso de profissionais liberais na política imperial, tal processo intensificara-se ainda mais, por razão da nova mobilidade possível.

Nessa conjuntura, a reforma eclesiástica colocada em prática pelos bispos de tendência ultramontana — que passaram a assumir as dioceses a partir de 1844 - também favorecera a perda de importância dos clérigos na política nacional, inibindo sua participação político partidária (SANTIROCCHI, 2010, p. 145). Entretanto, nem sempre as orientações das Cúrias eram as mesmas do Estado ou, até mesmo, congruentes com as da Santa Sé.

No caso específico da província de São Paulo, o bispo Antônio Joaquim de Mello possuía como meta a moralização e a normatização do clero, realizando uma ampla reforma em seu bispado a partir de moldes ultramontanos. Entretanto, apesar de a Cúria incentivar bispos a reformarem a Igreja através da ação na Câmara e no Senado, no episcopado paulista essa não era a orientação. A participação político-partidária do clero paulista (SANTIROCCHI, 2015, p. 185) fora combatida por seu bispo em exercício, já que este interpretava que os assuntos temporais estariam ligados à corrupção e ao reino das trevas (WERNET, 1987, p. 187).

Nesse contexto de perda da influência dos clérigos na esfera política institucionalizada, a formação tridentina e ultramontana tornara-se predominante nos seminários católicos, a partir do final da 
década de 1850 (SANTIROCCHI, 2010, p. 107). Diante disso, as novas circunstâncias delineadas pela crise de legitimidade do clero regalista no nível da política nacional e as tendências internacionais que definiriam o contexto da "romanização" alteraram a realidade brasileira do século XIX. Em respostas ao que era identificado como "vendaval das liberdades modernas” (CIARALLO, 2011, p. 93) - supostamente ameaçadoras à influência da Igreja católica sobre as sociedades civis - o papa Pio IX começou a expandir sua influência e jurisdição, decidindo mais sobre questões de disciplina e nomeações episcopais do que a própria Cúria (WERNET, 1987, p. 180).

É nessa conjuntura de transformação, iniciada no ano de 1840, que os jesuítas retornaram ao Brasil (DOMINGOS, 2014, p. 1). No que diz respeito à sua tradicional ação evangelizadora, buscando difundir o catolicismo desde o contexto da reforma protestante do século XVI, engajaram-se no processo colonizador português na América, na Ásia e na África desde a fundação da Ordem, em 1540. Subordinando-se ao Papa (COLSATO, 2017, p. 58), assumindo votos de pobreza, caridade e obediência total à doutrina da Igreja, os jesuítas transformam-se em um dos principais difusores da ortodoxia católica (COSTA et al., 2013, p. 1).

No caso brasileiro, os clérigos da Companhia de Jesus iniciaram sua missão em 1549, tornando-se muito influentes na administração e na educação na colônia. Através de sua política de instrução, edificaram templos e colégios nas mais diversas regiões da América portuguesa, obtendo o monopólio educacional. Baseada no Ratio - estatuto pedagógico composto por um conjunto de regras que envolvia desde a organização escolar até a observância da doutrina católica - e no humanismo, a pedagogia jesuítica "sempre teve em vista uma finalidade teológica de moldar a sensibilidade religiosa e o estudo conveniente das disciplinas" (WOOLEY, 2009, p. 13-14).

A educação desejada pelo Ratio tinha como objetivo a formação do homem perfeito e do bom cristão (FONSECA, 2006, p. 2) sendo adaptada conforme os costumes locais, seguindo a orientação das Constituições da Companhia de Jesus a fim de tornar a catequese mais eficaz (FONSECA, 2006, p. 1). Desde o primeiro colégio jesuíta, que existiu entre 1554 e 
1759, estes padres foram os únicos responsáveis pela educação no Brasil (FRANÇA, 1952, p. 88).

Nesse sentido, tais clérigos possuíam grande influência na sociedade, tanto por serem os responsáveis pela educação, quanto pela expansão da fé, transformando a interpretação dos indivíduos sobre a realidade. Além disso, na gama de seu amplo conjunto de atividades tanto no plano religioso quanto no político (SANTOS, 2008, p. 173) - o poder e influência dos jesuítas ultrapassavam esta criação de referenciais.

Por sua grande influência social, educacional, política e religiosa no Brasil - que os convertia num poder concorrente ao do Estado português - os jesuítas foram expulsos no ano de 1759, quando o Marquês de Pombal passou a interpretá-los como obstáculo à condução de sua política reformista (SILVA, 2006). No âmbito educacional, apesar das várias tentativas, as reformas educacionais de Pombal só desarranjaram "a sólida estrutura educacional construída pelos jesuítas". Nesse sentido, para o Brasil, "a expulsão dos jesuítas significou, entre outras coisas, a destruição do único sistema de ensino existente no país" (SECO; AMARAL, 2006, não p.).

Atuando também em diversos outros locais do globo, devido ao seu alcance e influência, duzentos anos após sua criação, a Companhia de Jesus fora suprimida entre 1773 e 1814 na Europa e em seus domínios, permanecendo vigente apenas na Rússia e na Prússia. É somente em 1814 que o Papa Pio VII restaura a Companhia de Jesus, possibilitando seu retorno às atividades eclesiásticas. Sendo reinstaurada no contexto do Congresso de Viena - marcado pelo restauracionismo das antigas Monarquias absolutistas em seus respectivos tronos, pela redefinição das fronteiras nacionais e pela formação da Santa Aliança — a Ordem retorna ao Brasil, buscando novamente difundir suas perspectivas do catolicismo, subordinando-se ao Vaticano. Este retorno implicou diversas estratégias de atuação junto à sociedade local, dentre as quais a educação.

Amparado nas contribuições da Nova História Política de matriz francesa - que define o político num sentido amplo, não restrito a uma suposta esfera de determinação da existência e sempre mutável (RÉMOND, 2003) - torna-se profícuo compreender também a educação como uma forma específica de articulação entre política e religião. No 
contexto analisado, portanto, é possível associar a atuação dos jesuítas no Brasil a uma influência tanto no que toca aos rumos assumidos pela reforma da Igreja - em moldes ultramontanos — quanto na redefinição dos nexos entre Igreja e Estado, observadas durante a segunda metade do século XIX. É sob este enfoque que o presente artigo busca analisar a atuação do núcleo jesuíta instalado em Itu, entre 1867 e 1918.

\section{A fundação do Colégio São Luís de Itu}

Provindos da Argentina no momento de seu retorno ao Brasil, os clérigos jesuítas percorreram o Rio Grande do Sul, Paraná e Santa Catarina, posteriormente encaminhando-se para Nova Friburgo e Itu (LOCHER, 1914, p. 55-57). Fundada em 1610, a então vila de Itu abrigou a existência de um processo histórico singular no século XIX e início do XX, possuindo mais ordens religiosas do que São Paulo, então capital da Província (CAVALHEIRO, 2001, p. 5).

Sendo chamada de "Centro do Liberalismo Paulista" e "Roma Brasileira” (CAVALHEIRO, 2001, p. 15), o local apresentava-se como antigo reduto patrocinista - grupo formado por clérigos com uma leitura particular do catolicismo, que associava política e religião em diversos níveis e integrava Igreja e Estado em um só corpo - possuindo como tendência hegemônica o regalismo, até a década de 1840 .

Tal conjuntura foi profundamente transformada com a chegada dos clérigos jesuítas Antonio Onorati, Bartolomeu Taddei, irmão José Giommi e irmão coadjutor Afonso d'Amicis, no ano de 1865 (COLSATO, 2017, p. 71). Por defenderem a subordinação da Igreja e de seus fiéis ao Vaticano e aos ditames do Concílio de Trento, tais clérigos foram responsáveis por uma ruptura com o modelo de catolicismo hegemônico até então. Apesar de tal reorientação ser uma tendência geral na província de São Paulo (AZEVEDO, 1988, p. 201), a existência de ambas as vertentes em Itu proporciona uma especificidade ao campo religioso local.

No que diz respeito aos fatores econômicos, Itu fora considerada a vila mais rica da província no século XIX, apoiando-se no cultivo do açúcar e posteriormente do café (DOMINGOS, 2014, p. 169). Ao 
mesmo tempo, dispunha da possibilidade de cultivar algodão e, através do incentivo inglês, a vila inaugura a primeira fábrica de tecidos bem-sucedida da província (CAVALHEIRO, 2001, p. 36). Sendo considerada a capital econômico-cultural depois de São Paulo, sua situação próspera chamou a atenção de um visitador jesuíta, que considerou a possibilidade da abertura de um colégio no local, que contava com famílias prósperas em condições de financiar os estudos de seus filhos (DOMINGOS, 2014, p. 170).

Estabelecendo-se em Itu, em 1865, tais clérigos passaram a constituir um grupo social, defendendo e buscando legitimar diversas ideias opostas às do grupo patrocinista. Buscando propagar sua visão do catolicismo, desenvolveram atividades evangelizadoras e educacionais no local, iniciando os trâmites para a abertura de um colégio. Entretanto, devido ao recente reestabelecimento dos jesuítas no território brasileiro, o debate sobre a laicização da educação, então em curso, e o fato de todos os clérigos pertencentes ao núcleo inicial serem estrangeiros (T\&M, 2007), observou-se uma resistência em alguns dos setores políticos locais. Exemplo disso é que o Inspetor Provincial da Instrução Pública da época, Diego de Mendonça, negou a licença para o funcionamento da instituição.

Não aceitando a negativa, os padres Onorati e Taddei elaboram estratégias de atuação social, legitimando seu projeto de abertura de um colégio com o auxílio da população. Contando com o apoio de Antonio Augusto Guaianaz e do tenente Luciano Francisco de Lima, fora expedido um pedido de abertura da instituição à corte, o qual fora concedido em 1867, quando os jesuítas estavam a ponto de desistir da abertura deste colégio (T\&M, 2007).

Influenciado pelas reformas elaboradas por D. Antônio Joaquim de Mello, o catolicismo de tendência ultramontana fortificara-se no território, concedendo respaldo para a difusão do ensino religioso católico que havia sido uniformizado (SANTIROCCHI, 2015, p. 185). Num momento em que se buscava solidificar a catequese, a formação de clérigos e a regulamentação das devoções populares (SANTIROCCHI, 2015, 185), as especificidades da ação educacional e catequética jesuítica vieram a calhar. 
Nesse sentido, apesar de não se configurar especificamente num preceito episcopal, a abertura do Colégio e a atuação educacional dos jesuítas demonstram uma afinidade entre as intenções do bispado e as da Ordem. Entretanto, de certa forma é contrária à orientação da despolitização do clero defendida por D. Antônio Joaquim de Mello, então bispo de São Paulo, já que por meio de tal atuação, tais clérigos exerceriam uma forte influência na sociedade local e, principalmente, nos grupos mais abastados financeiramente.

Sendo capaz de formar e difundir determinados habitus, a educação jesuítica balizada no Colégio São Luís se mostra relevante para a compreensão dessa conjuntura específica, na qual as disputas por legitimidade entre Igreja e Estado, assim como entre catolicismo e protestantismo, alcançaram também o âmbito educacional. Isso porque "[...] o político também pode ser um objeto de conhecimento científico assim como fator de explicação de outros fatos para além de si mesmo" (RÉMOND, 1999, p. 51).

\section{Religião e Política na pedagogia do Colégio São Luís}

Inaugurado em 12 de maio de 1867 (TIPOGRAFIA BRASIL, 1917), o Colégio São Luís em seu primeiro ano de funcionamento já contava com setenta estudantes e, em 1894, o número de alunos ultrapassava os seiscentos, extrapolando as expectativas da Igreja Romana, por receber alunos de quase todas as províncias brasileiras (CAVALHEIRO, 2001, p. 7). É válido salientar que sua influência não se restringia às classes abastadas, pois, possuindo alunos "bolsistas" o Colégio fora capaz de englobar, também, as classes economicamente menos favorecidas (COLSATO, 2017, p. 83-84).

No século XIX, lecionavam-se no Colégio Línguas, História Natural, Geografia, Aritmética, Álgebra, Geometria, Química e "Physica” — matéria dedicada à moral e a formação de um bom cristão (TIPOGRAFIA BRASIL, 1917), sendo este um dos principais objetivos da educação jesuítica. Para alcançá-lo, a "proibição de livros inconvenientes" era realizada, a fim de que os alunos não os lessem "[...] para que a natureza do conteúdo não 
ofenda a pureza da alma" (FRANÇA, 1952, p. 130). Também, autores "infesos ao cristianismo" - como alguns "intérpretes de Aristóteles" não deveriam ser lidos ou citados em hipótese alguma (FRANÇA, 1952, p. 159).

Intrinsecamente religiosa, tal concepção era legitimada ainda pela obrigatoriedade da realização de oração antes das aulas (FRANÇA, 1952, p. 144) e da aceitação das "explicações dos Papas e Concílios", afirmando que "[...] literal ou místico, este é indubitavelmente o seu sentido" (FRANÇA, 1952, p. 149). Além disso, seria obrigação dos professores das "classes inferiores" recitar orações, comparecer à missa, recitar de cor a doutrina cristã, realizar "uma exortação espiritual ou explicação da doutrina" e confessar-se semanalmente, participar de colóquios espirituais, realizar "leituras espirituais" principalmente sobre a vida dos santos, rezar nas aulas ladainhas de Nossa senhora e rezar pelos alunos (FRANÇA, 1952, p. 181-182).

Seguindo o modelo do internato, a vigilância "do tempo e das ações dos jovens era maneira de estabelecer um controle sobre a própria circulação de ideias, criando um universo a parte" (COLSATO, 2017, p. 83). Os alunos, por sua vez, deveriam participar de missas, confessar mensalmente e seguir a doutrina cristã, participando do catecismo. Também deveriam "fugir das más companhias" que "atrapalhariam o estudo e a virtude", além de abster-se de livros "perniciosos" e de espetáculos e teatros (FRANÇA, 1952, p. 220-221). Nesse sentido, como pretendido, observa-se um caráter fortemente moral e religioso emprestado à educação jesuítica do núcleo ituano, criando e legitimando um habitus religioso ligado aos valores defendidos pela Ordem, a fim de converter professores e alunos ao que consideravam um bom cristão.

Tal ideal revelava-se congruente ao objetivos da reforma ultramontana em curso, uma vez que esta tendeu a afirmar a autoridade de uma igreja institucional e hierárquica, diretamente subordinada a Roma e cada vez mais dependente de padres estrangeiros pertencentes às congregações e ordens missionárias, enviados ao Brasil com a função de "controlar a doutrina, a fé, as instituições e a educação do clero e laicato" (SANTIROCHI, 2010). 
Além disso, vale atentar para um aspecto conjuntural, capaz de esgarçar os profundos nexos entre religião e política naquele momento e reforçar a importância então conferida pela Ordem ao aspecto educacional como estratégia de influência junto à sociedade civil. Trata-se do estágio galgado pelo debate acerca da imigração estrangeira, a partir da década de 1850, quando a extinção do tráfico passou a impor a viabilização da imigração de europeus para a formação do mercado de trabalho livre ${ }^{1}$ e quando a "quantidade de missionários protestantes que vinham, especialmente, dos Estados Unidos para evangelizar os brasileiros já era significativa" (PEREIRA, 2008, p. 106). Neste cenário, o "ordenamento jurídico imperial foi alargando os limites à liberdade religiosa”, opondo à "minoria fiel ao Vaticano", uma elite política que, crescentemente, assumia a liberdade religiosa como mais um ícone da modernidade ocidental, apoiando e consolidando a "ideia de que o Estado brasileiro devia ampliar ao máximo as liberdades individuais no que dizia respeito à fé" (PEREIRA, 2008, p. 109).

Assim, enquanto nas localidades próximas a educação de viés protestante se legitimava, em Itu "o projeto educacional protestante foi obstacularizado pelos padres jesuítas” (CAVALHEIRO, 2001, p. 42), de forma a minar a influência deste principal concorrente no campo religioso cristão. Interligando toda a sociedade através de rituais devocionais que perpassavam o Colégio, tal ação tornou-se tão legítima que até os dias de hoje não houve notícias de qualquer denominação evangélica que tenha conseguido legitimar sua concepção educacional com sucesso em Itu (CAVALHEIRO, 2001, p. 7). Isto demonstra a eficácia da construção de um longevo habitus educacional, implantado pelos jesuítas neste local.

Dessa forma, atuando como "porta vozes da oposição às mudanças políticas propostas pelo grupo dos liberais, condenando o ensino laico descolado da educação religiosa" (COLSATO, 2017, p. 15), na perspectiva desses clérigos o Colégio seria responsável por formar indivíduos capazes de assumirem os diversos papéis sociais por eles considerados importantes.

1 Vale lembrar que, entre os anos de 1850 e 1870, a maior parte do contingente migratório que entrou no Brasil, para suprir a demanda por mão de obra, era oriundo de terras germânicas, onde a maioria da população era protestante. 
Afinal, é a partir da chamada "geração de 1870" que novas ideias de cunho cientificista passam a invadir o Brasil, sendo incorporadas pelas elites intelectuais e políticas como os novos ícones da modernidade ocidental, chocando-se frontalmente com o tradicionalismo da Igreja Católica (ALONSO, 2002). Assim: a legitimidade política e moral do catolicismo exigia que este se identificasse (ainda que seletivamente) aos ideais modernos, inserindo os jesuítas do núcleo ituano num contexto em que as ciências e a política não poderiam ser facilmente excluídas da educação, levando-os a interpretar estes ícones da modernidade em voga pelo viés religioso (MENSAGEIRO DO CORAÇÃO DE JESUS, tomo 1, n. 2, 1896, p. 103).

Sendo este Colégio diretamente ligado ao ensino religioso, num momento em que o Estado se reorganizava - uma vez que a Constituição de 1891 punha fim ao padroado e que, desde o Decreto 7 de janeiro do ano anterior, era instituída a liberdade religiosa no Brasil, ganhando relevo a vertente liberal da secularização - observa-se uma disputa pela legitimidade em relação ao ensino. Mais do que isso, o Colégio não pode abster-se das novas configurações gestadas pelo Estado republicano para legitimar-se.

Intencionando demonstrar a suposta importância do ensino religioso para a legitimação da nação e do nacionalismo e, ao mesmo tempo, defendendo uma relação teoricamente não conflituosa entre a formação religiosa e política dos indivíduos, tais clérigos defendiam a formação de "cidadãos de bem" (MADUREIRA, 1927, p. 598). Para tanto, lecionavam no Colégio o "ensino cívico", que, apesar de não ser uma diretriz do Ratio, configurava-se em uma adaptação pedagógica às contingências locais. Tal conjuntura pode demonstrar a necessidade de difundirem concepções políticas a partir de um viés religioso, numa perspectiva de condicionamento e exclusão de determinadas ideologias e afirmação de outras, consideradas adequadas por aqueles padres.

Nessa perspectiva, observa-se que a construção do cidadão como novo sujeito político e do patriotismo como sentimento capaz de dar coesão à sociedade política, eram orientados pela religião católica — tida como a única verdadeira, conforme a concepção ultramontana - e pelo modelo institucional da própria Igreja, concebida como "Sociedade Perfeita", 
superior e independente de qualquer outra instituição (CORDI, 1984, p. 34).

Da mesma forma, a fusão entre fundamentos aspectos religiosos e políticos era fundamentada no exemplo histórico dos grandes acontecimentos e personagens, revelando a forte influência das concepções historiográficas do século XIX, de cariz positivista e historicista. Assim, portadores da verdadeira religião e de um dos principais instrumentos da construção das sociedades modernas - a educação - os jesuítas buscavam galgar legitimidade junto ao próprio Estado, nesse momento do retorno da Ordem ao Brasil.

Entretanto, apesar de proporem o ensino cívico - demonstrando consideração em relação ao novo modelo de Estado em voga (MADUREIRA, 1927, p. 598) - a pedagogia do núcleo jesuíta de Itu não podia ignorar o fato de que, naquele momento, estava em curso o processo de diferenciação entre o ensino religioso e o laico (TIPOGRAFIA BRASIL, 1917). Assim, preocupados com a formação de clérigos - capazes de orientar a sociedade e os rumos da sociedade moderna e secular em construção - reforçaram o ensino religioso, criando, anexo ao Colégio, um seminário - divulgado como "Escola Apostólica". Desse modo, davase ênfase simultânea à formação religiosa de leigos e à formação sacerdotal (LOCHER, 1914, p. 57).

Tal ação não foi isenta de conflitos, uma vez que Estado e Igreja buscavam normatizar colégios e escolas apostólicas a seu modo e, consequentemente, a favor dos seus respectivos ideais, nem sempre afinados. Assim, se por um lado é possível identificar a orientação religiosa do Colégio São Luís, por outro, havia uma tentativa do ensino religioso, voltado para a formação de clérigos, de afirmar-se sobre o laico (TIPOGRAFIA BRASIL, 1917), emprestando à atuação educacional desses clérigos um caráter concorrente ao poder político, no aspecto educacional.

Apesar do crescente sucesso do Colégio, as epidemias que atingiram diversas cidades do interior de São Paulo nos últimos anos do século XIX, chegaram a Itu, transformando tal conjuntura. Tal situação refletiu-se no Colégio, que enfrentava dificuldades para manter-se devido à escassez de professores jesuítas. Por essas razões, impôs-se encontrar um novo local para o estabelecimento (T\&M, 2007). 
Em meados do século XIX, São Paulo perdia, progressivamente, seu caráter provinciano. O surgimento de casas, alargamentos das ruas e formação de novos bairros transformavam o local e as novidades trazidas pela modernidade colaboravam para tais mudanças. Tal conjuntura fora julgada adequada para a transferência do Colégio para uma nova avenida que começava a surgir na cidade, ocupada por casarões e inaugurada em 1891: a "Avenida Paulista".

Considerando o caráter simbólico de novidade e inovação que esse espaço recebera no momento, sua escolha como novo local para instalação do Colégio, em 1918, não nos parece ter sido aleatória. Se em seu discurso e pedagogia tais jesuítas buscavam legitimar uma relação possível entre modernidade e catolicismo, a alteração do espaço do Colégio pode significar, neste âmbito, a materialização dessa concepção. Assim, a transferência e refundação do Colégio seria uma forma de, simultaneamente, dotar-lhe de visibilidade social e legitimidade política, atraindo não apenas apoio do governo provincial, mas da elite abastada da nova metrópole em formação, viabilizando-o, também, financeiramente.

Em funcionamento no mesmo endereço até os dias de hoje, o Colégio São Luís nos parece ter sido capaz de influenciar os debates e embates entre prostestantismo e catolicismo, Estado e Religião, ensino religioso e laico. Alterando e difundindo um habitus (BOURDIEU, 1974) intrinsecamente religioso - e, especificamente ligado aos preceitos da Companhia de Jesus - a partir da educação, para além da então vila de Itu, tais clérigos foram responsáveis por alterar e influenciar as relações entre educação, política e religião no Brasil de finais do século XIX ao começo do XX.

\section{Considerações finais}

Enquanto expressões socioculturais historicamente situadas, as mudanças nos fenômenos religiosos nos permitem identificar articulações com mudanças produzidas em outras esferas da realidade, como a política, a sociedade e a cultura (JULIA, 1976). Nesse sentido, 
consideramos a religião e seus desdobramentos enquanto fenômenos historicamente situados.

No Brasil, somente após a relativa definição do Estado e Nação brasileiros, na segunda metade do século XIX, é que a vertente ultramontana do catolicismo galgou condições para assumir visibilidade social e legitimidade política. Apesar das especificidades relativas à Ordem dos jesuítas, o que se pode perceber é uma afinidade eletiva entre sua atuação e o ultramontanismo, a partir da qual se revelam os nexos entre religião e política no contexto recortado.

A partir da perspectiva teórica aberta pela Nova História Política, com a ampliação do próprio conceito de "político" - irrestrito à esfera da política institucional —, é possível expandir a análise e considerar a função política da educação jesuítica. A redefinição dos mecanismos e estratégias de articulação entre religião e política, portanto, pode iluminar novas perspectivas para questões em debate, como no caso da suposta despolitização do clero ultramontano paulistano, difundida por D. Joaquim de Mello e reiterada por uma dada vertente da historiografia brasileira (SANTIROCCHI, 2011).

Uma das estratégias por eles aventada configurou-se na abertura do Colégio São Luís, em funcionamento até os dias de hoje na cidade de São Paulo. Seguindo o modelo de internato (COLSATO, 2017, p. 83) e de caráter intrinsecamente religioso, os jesuítas que adentraram a região de Itu caracterizaram-se como "porta vozes da oposição às mudanças políticas propostas pelo grupo dos liberais, condenando o ensino laico descolado da educação religiosa" (COLSATO, 2017, p. 15).

Fixando-se na região em 1865, tais clérigos constituíram-se como grupo social, buscando legitimar-se perante a sociedade local e, também, como braço do ultramontanismo, que naquele momento galgava legitimidade política junto ao governo imperial. Assim, se por um lado posicionaram-se como "porta-vozes da oposição às mudanças políticas propostas pelo grupo dos liberais, condenando o ensino laico descolado da educação religiosa" (COLSATO, 2017, p. 15), por outro, não puderam manter-se afastados da política, exercendo forte influência na sociedade local e, principalmente, junto aos grupos mais abastados financeiramente, formando diversos alunos que envolveram-se diretamente na política 
- assumindo cargos como Presidente e Vice-Presidente de Província (TIPOGRAFIA BRASIL, 1917) —, demonstrando, assim, a dimensão político-institucional do habitus ministrado por sua pedagogia.

Da mesma forma que revelaram uma atuação política, tais jesuítas não puderam abdicar totalmente das novas concepções e valores em voga, associados à modernidade ocidental. Num momento em que católicos e protestantes disputavam o monopólio de legitimidade no âmbito educacional e em que ganhava legitimidade a vertente laica da secularização no Brasil, os jesuítas não puderam abrir mão dos novos preceitos educacionais da época para se legitimarem. Nesse sentido, parece-nos válido considerar que estes clérigos realizaram adaptações em sua pedagogia, atuação e estratégias, revelando-se, eles próprios, agentes da construção de uma sociedade moderna e secular.

Neste sentido, a abordagem aqui desenvolvida dialoga criticamente com algumas das teses clássicas das Ciências Sociais no Brasil, que tenderam a criar a tradicional imagem do Estado como tendendo a secularizar e a Igreja e seus agentes como resistindo a tal processo (STEIL; HERRERA, 2010). Por interpretarem a experiência brasileira a partir dos modelos herdados das teorias gerais da modernidade e da secularização - em particular, o modelo dos "tipos ideais" weberiano, que tenderam a estabelecer tipologia para os catolicismos brasileiros feita em função da maior ou menor adesão ao catolicismo oficial, às suas crenças, normas e observâncias - tais estudos conceberam o catolicismo como elemento atávico de nossa formação, impondo resistência à construção de uma sociedade moderna e secular, não considerando sua dinâmica capacidade de adaptação e reconfiguração em resposta às transformações observadas em outras esferas da realidade, como a política, a economia, a sociedade, a ciência.

\section{Referências}

ASAD, T. Formations of the Secular: Christianity, Islam, modernity. California: Stanford, 2003. 
ALONSO, A. Ideias em Movimento: a geração 1870 na crise do Brasil - Império. São Paulo: Paz e Terra, 2002.

AZEVEDO, F. A inesperada trajetória do ultramontanismo no Brasil Império. Perspectiva Teológica, n. 20, p. 201-218, 1988.

BOURDIEU, P. A Economia das Trocas Simbólicas. São Paulo: Perspectiva, 1974.

CAVALHEIRO, D. Hegemonia católica e educação da elite em Itu (1851-1889), o Colégio N.S. do Patrocínio (feminino) e o Colégio São Luíz Gonzaga (masculino). Piracicaba: Universidade Metodista de Piracicaba, 2001.

CIARALLO, G. O tema da liberdade religiosa na política brasileira do século XIX: uma via para a compreensão da secularização da esfera política. Revista de Sociologia Política, Curitiba, v. 19, n. 38, p. 85-99, fev. 2011.

COLSATO, A. Organização hierárquica e linguística: o modelo jesuítico após a restauração. Tese (Doutorado em Letras) - Universidade de São Paulo, São Paulo, 2017.

CORDI, C. O tradicionalismo na República Velha. Tese (Doutorado em Filosofia) — Universidade Gama Filho, Rio de Janeiro, 1984.

COSTA, J. et al. Companhia de Jesus nos séculos XVI: suas influências nos territórios português, indiano e brasileiro.In: CONGRESSO INTERNACIONAL DE HISTÓRIA, 6., 2013, Maringá. Anais... Maringá: UEM, set. 2013.

DOMINGOS, S. Política e Religião: repercussões da polêmica sobre o retorno dos jesuítas no Brasil durante o Segundo Reinado (1840-1870). Tese (Doutorado em Ciências da Religião) — Universidade Estadual de Campinas, Campinas, 2014.

FONSECA, S. A Hegemonia Jesuítica (1549-1759). In: HISTEDBR, Campinas, 2006. Disponível em: <http://www.histedbr.fe.unicamp.br/navegando/periodo_jesuitico_intro.html>. Acesso em: 24 jun. 2016.

FRANÇA, L. O método pedagógico dos jesuitas. O "Ratio Studiorum". Rio de Janeiro: Agir, 1952.

HAUPT, H.-G. Religião e nação na Europa no século XIX: algumas notas comparativas. Estudos Avançados, São Paulo, v. 22, n. 62, p. 77-94, 2008. 
HERVIEU-LÉGER, D. La modernité rituelle: rites politiques et religieux des sociétés modernes. Paris: l'Harmattan, 2004.

JULIA, D. História religiosa. In: LE GOFF, J.; NORA, P. (Org.). História: novas abordagens. Rio de Janeiro: Francisco Alves, 1976. p. 106-131.

LOCHER, G. A companhia de Jesus: Centenário da sua Restauração. Porto Alegre: Tipografia do Centro, 1914.

MADUREIRA, I. A liberdade dos indios, a Companhia de Jesus: sua pedagogia e seus resultados. Rio de Janeiro: Imprensa Nacional, 1927.

MENSAGEIRO DO CORAÇÃO DE JESUS. 1896-1900. Disponível em: <http:// www.mensageirodosagradocoracao.com.br/revista.asp.>. Acesso em: 24 jun. 2016.

PEREIRA, R. N. M. A primeira das liberdades: o debate político sobre a liberdade religiosa no Brasil Imperial. Desigualdade \& diversidade, Rio de Janeiro, v. 1, p. 6, 2007.

PEREIRA, R. N. M. A salvação do Brasil: as missões protestantes e o debate político-religioso do século XIX. Tese (Doutorado em História Política) — Universidade Estadual do Rio de Janeiro, Rio de Janeiro, 2008.

RÉMOND, R. (Org.). Por uma história política. Rio de Janeiro: FGV, 2003.

RÉMOND, R. O retorno do político. In: CHAVEAU, A.; TÉTARD, P. (Orgs.). Questões para a história do presente. Bauru: EDUSC, 1999.

SANTIROCCHI, I. Os ultramontanos no Brasil e o regalismo do Segundo Império (1840-1889). Tese (Doutorado em História) — Pontifícia Universidade Gregoriana, Roma, 2010.

SANTIROCCHI, I. Afastemos o padre da política! A despolitização do clero brasileiro durante o Segundo Império. MNEME - Revista de Humanidades, v. 12, n. 29, p. 187-207, jan./jul. 2011.

SANTIROCCHI, I. Questão de consciência: os ultramontanos no Brasil e o regalismo do Segundo Reinado (1840-1889). 1. ed. Belo Horizonte: Fino Traço, 2015. 
SANTOS, F. A expulsão dos jesuítas da Bahia: aspectos econômicos. Revista Brasileira de História, n. 28, p. 95-171, 2008.

SECO, A.; AMARAL, T. Marquês de Pombal e a reforma educacional brasileira. HISTERDBR, Campinas, 2006. Disponível em: <http://www.histedbr.fe.unicamp. br/navegando/periodo_pombalino_intro.html>. Acesso em: 24 jun. 2016.

SILVA, A. R. C. Inventando a Nação. Intelectuais Ilustrados e Estadistas Luso-Brasileiros na Crise do Antigo Regime Português: 1750-1822. 1. ed. São Paulo: HUCITEC, 2006.

SILVA, A. R. C.; LOURENÇO, L. S. Entre a política e a religião: uma análise da imprensa periódica feijoísta, na conjuntura de 1834 a 1835. Revista Brasileira de História das Religiões, v. 7, p. 207-229, 2015.

STEIL, C. A.; HERRERA, S. R. Catolicismo e Ciências Sociais no Brasil: mudanças de foco e perspectivas num objeto de estudo. Sociologias, Porto Alegre, ano 12, n. 23, p. 354-393, jan./abr. 2010.

T\&M. Colégio São Luís: A educação e os Jesuítas no Brasil (140 anos). São Paulo: T\&M, 2007.

TIPOGRAFIA BRASIL. Lembrança do 50 aniversário do Colégio São Luís em Itu (1867-1917). São Paulo: Tipografia Brasil, 1917.

WERNET, A. A Igreja Paulista no século XIX: a reforma de D. Antônio Joaquim de Melo (1851-1861). São Paulo: Editora Ática, 1987.

WOOLLEY, P. Os jesuítas no setecentos europeu: autoridade, ensino e poder. Revista Cantareira, 6. ed., 2009.

Recebido: 09/12/2017

Received: 12/09/2017

Aprovado: 11/03/2019

Approved: 03/11/2019 